\title{
La prohibición de ir contra acto propio como manifestación de la exigencia al consumidor de actuar conforme a los parámetros de la buena fe (Corte de Apelaciones de Santiago)
}

\section{Comentario de María Elisa Morales Ortiz*}

Santiago, treinta de enero de dos mil catorce.

\section{VISTOS:}

Se reproduce la sentencia en alzada, con excepción de sus motivos tercero a decimotercero, que se eliminan. En su motivo segundo, se suprime la frase "atravesado o colgado de la pasarela denominada Las Golondrinas”.

\section{Y TENIENDO EN SU LUGAR Y, ADEMÁS, PRESENTE:}

$1^{\circ}$ ) Que una de las alegaciones de la parte demandada es que no ha habido culpa de su parte en el resultado dañoso conocido en estos antecedentes pues aquél se produjo por caso fortuito. Al respecto se debe tener presente que el artículo 45 del Código Civil señala que "Se llama fuerza mayor o caso fortuito el imprevisto a que no es posible resistir, como un naufragio, un terremoto, el apresamiento de enemigos, los actos de autoridad ejercidos por un funcionario público, etc. En doctrina y jurisprudencia se señalan como requisitos del caso fortuito y de la fuerza mayor, los siguientes: a) el hecho debe ser generado por una causa extraña a la voluntad del deudor; b) el hecho debe ser imprevisto; y c) el hecho debe ser irresistible (Tratado de las Obligaciones, Alessandri, Somarriva y Vodanovic, Editorial Jurídica, Segunda Edición, 2004, páginas 278 a 281).

$2^{\circ}$ ) Que el hecho deba ser generado por una causa extraña a la voluntad del deudor significa que éste no ha debido contribuir de ninguna manera a causarlo. Lo anterior aparece consagrado en el inciso segundo del artículo 1547 del Código Civil. En el caso sub judice no hay prueba que convenza a estos sentenciadores de que el día 17 de septiembre de 2011, aproximadamente a las 18:00 horas, colgaba de la pasarela Las Golondrinas de

* Abogada. Candidata a doctora en derecho por la Universidad de Chile. Becaria Conicyt. Profesora de Derecho del Consumidor en la Facultad de Derecho de la Universidad Alberto Hurtado. Correo electrónico: elisa.moralesortiz@gmail.com. 
la Autopista del Sol un hilo llamado popularmente "curado (o sea, un hilo al que se le han agregado elementos cortantes como vidrio molido o fierro molido), que significó que el actor, que circulaba por dicha vía en motocicleta, tuviera una herida cortante en su cabeza que tuvo que ser suturada con 25 puntos. Es cierto que el accidente se produjo, que efectivamente un hilo "curado hirió al demandante en la carretera, en el día y a la hora señalada, pero las probanzas rendidas para demostrar que dicho hilo colgaba de la pasarela Las Golondrinas se estrellan contra la propia declaración prestada por el demandante al canal de televisión Chilevisión, en grabación acompañada por él, vista y oída por esta Corte, en que refiere que en el lugar, en el día y a la hora señalados, iba en una motocicleta y vio que "el hilo venía cerca de su cara y que "alcancé a ver el volantín, pero el hilo no pero cuando estaba cerca de mi cara lo alcancé a ver, o sea, flotaba en el viento un volantín "cortado, con su respectivo hilo "curado, volantín que vio el actor y cuyo hilo le produjo la herida en el rostro; no es efectivo, entonces, según la propia declaración del demandante prestada ante el canal de televisión aludido, que el hilo haya estado colgando del puente o pasarela Las Golondrinas, como afirma en su demanda. Luego, no se trata de un caso en que la demandada, Concesionaria Autopista del Sol S.A., por falta de mantención, no haya removido hilos "curados colgando de la pasarela sino de una situación ajena a su accionar, en que un volantín cortado, del que pendía hilo curado, desplazándose por el aire, produjo las lesiones al actor, según se ha encargado éste de señalarlo en la mencionada entrevista. Cabe agregar que en el mismo documento audiovisual de Chilevisión acompañado por el denunciante se hace ver la gran cantidad de volantines cortados que están enredados en árboles cercanos a la carretera en cuestión.

$3^{\circ}$ ) Que la imprevisibilidad del hecho está referida a que ninguna razón hay para esperar su ocurrencia, que racionalmente no existe manera de anticipar su ocurrencia. Y no se ve cómo la demandada Sociedad Concesionaria Autopista del Sol S.A. haya podido anticipar que se cortara un volantín que estaba siendo elevado con hilo curado. Ahora bien, cierto es que en el mes de septiembre tradicionalmente se elevan volantines y que en algunos casos se ocupa para ello hilo curado, pero también es efectivo que este requisito implica que no hubo posibilidad de prever que, precisamente, en ese día y a esa hora, se cortara un volantín de estas características, que se desplazara por el aire en dirección a la carretera y que cortara en la cara al actor. Que haya existido la posibilidad de que tal cosa sucediera no importa que la sociedad demandada haya podido prever tal acontecimiento. Su obligación consiste en mantener la carretera apta para el tránsito seguro y ello no puede incluir el adivinar cuando un volantín elevado con hilo curado en septiembre se corte y se desplace hacia la carretera y, en todo caso, tampoco se advierte qué medida habría podido tomar para impedirlo.

$4^{\circ}$ ) Que el hecho sea irresistible implica que no es posible evitar sus consecuencias. Nos remitimos a lo dicho precedentemente y, por lo tanto, el accidente en cuestión debe ser calificado como irresistible. 
$5^{\circ}$ ) Que, en consecuencia, la denuncia infraccional y demanda civil de don Renato Segundo Pérez Martínez, en cuanto se fundan en que al pasar bajo el puente o pasarela Las Golondrinas se percató que "del puente colgaban varios hilos y que "uno de estos hilos se enredó en su casco, lo cortó y le produjo las lesiones que efectivamente tuvo, atenta contra la doctrina de los actos propios (venire contra propium factum nulli conceditur), que constituye un principio general del derecho que, evidentemente, informa todo nuestro ordenamiento jurídico. En efecto, como se ha dicho por esta Corte y por la Excma. Corte Suprema de Justicia, tal doctrina se traduce en que se debe mantener en el derecho una conducta leal y honesta y, desde luego, es la inspiración de la regla por la cual nadie puede aprovecharse de su propio dolo o fraude, encontrando en materia contractual su base legal en el referido artículo 1546 del Código Civil. Son requisitos de procedencia de esta teoría: a) una conducta anterior, que revela una determinada posición jurídica de parte de la persona a quien se le trata de aplicar este principio; b) una conducta posterior por parte del mismo sujeto, contradictoria con la anterior; y c) que el derecho o pretensión que hace valer la persona a quien incide el actor perjudique a la contraparte jurídica.

$6^{\circ}$ ) Que así, no es atendible una pretensión procesal como la del demandante que está en abierta contradicción con la conducta demostrada anteriormente, al afirmar ante un canal de televisión que vio un volantín que se desplazaba hacia él y que también vio el respectivo hilo curado "cuando estaba cerca de su cara", para luego afirmar en su demanda que tal hilo "colgaba del puente o pasarela Las Golondrinas”.

$7^{\circ}$ ) Que tampoco el daño ha podido deberse a una supuesta negligencia de la denunciada y demandada en auxiliar al actor, pues como él mismo señala en su demanda, fue conducido por particulares a un centro médico, donde fue atendido y suturado, de manera que no hay nexo causal entre los perjuicios que dice haber experimentado y la pretendida desidia de la Concesionaria Autopista del Sol en auxiliarlo”.

$8^{\circ}$ ) Que debe recordarse que la llamada Ley de Protección al Consumidor $\mathrm{N}^{\circ} 19.496$ exige del proveedor, para que éste responda de acuerdo a ese estatuto, "negligencia, la que no sólo no se ha acreditado en la prestación de los servicios a que está obligada la demandada sino que, al contrario, se encuentra demostrado en el proceso, con los propios dichos del actor, que el daño se debió a fuerza mayor o caso fortuito.

$\left.9^{\circ}\right)$ Que, entonces, establecido lo anterior, resulta inoficioso apreciar y ponderar la prueba rendida acerca de la naturaleza y monto de los daños.

Y visto, además, lo dispuesto en el artículo 32 de la ley 18.287 , se revoca la sentencia de doce de junio de dos mil trece, escrita de fojas 138 a 148 y en su lugar se decide que se absuelve a Sociedad Concesionaria Autopista del Sol S.A. de la denuncia formulada en su contra en lo principal de fojas 2 y que se rechaza la demanda civil del primer otrosí de la misma presentación, sin costas por haber tenido motivos plausibles para litigar. 
Redacción del Ministro señor Mera.

Regístrese y devuélvase con su agregado.

$\mathrm{N}^{\mathrm{o}} 1.7312013$.

Pronunciada por la Duodécima Sala, presidida por el Ministro señor Juan Cristóbal Mera Muñoz e integrada por la Ministra señora Marisol Rojas Moya y la Ministra Suplente señora Maritza Elena Villadangos Frankovich.

Autoriza el (la) ministro de fe de esta Iltma. Corte de Apelaciones de Santiago.

En Santiago, treinta de enero de dos mil catorce, se notificó por el estado diario la resolución que antecede.

En la aplicación de un estatuto protector, como lo es la ley de protección de los derechos de los consumidores ${ }^{1}$, es escaso encontrar fallos que reprochen la actuación de la parte más débil.

Aunque parezca evidente, es necesario explicitar aquí que si bien la LPDC busca proteger al consumidor, intentando resolver la asimetría existente entre éste y su contraparte, sabido es que el parámetro de la buena fe objetiva es exigido a ambas partes de la relación jurídica, por igual. Por más obvio que resulte este razonamiento, en sede de consumidor existen casos en que los Tribunales han dado preferencia al principio de defensa del consumidor. ${ }^{2}$

La sentencia que se comenta, resulta interesante porque califica la conducta del consumidor a la luz de una de las manifestaciones del principio de la buena fe, estimando aplicable la regla del venire contra factum propium non valet.

Esta teoría, denominada doctrina de los actos propios, se levanta sobre la observación de "una conducta que justifica la conclusión o creencia de que no se hará valer un derecho, sea porque éste no existe o de existir no se hará efectivo" ${ }^{3}$. A su vez, encuentra su fundamento en la buena fe objetiva ${ }^{4}$, principio del cual se desprende "como consecuencia inmediata y necesaria" el repudio hacia conductas que vayan en contra de otras anteriores $^{5}$. Se trata entonces de un corolario de este principio general del derecho,

${ }^{1}$ Ley 19.496, que establece normas sobre protección de los derechos de los consumidores, publicada en el Diario Oficial el 7 de marzo de 1997. En adelante LPDC.

${ }^{2}$ Así ocurrió en el denominado caso Dell, como lo señala Barrientos: Barrientos, F. “Comentario. Ámbito de aplicación de la Ley N 19496 de 1997. Negativa injustificada de la venta. Oferta promocional. Formación del consentimiento. Computadores portátiles a bajo precio. Buena fe del consumidor. Tercera Sala Corte de Apelaciones de Santiago, 12 de marzo de 2012, rol No 8470-2010 y Juzgado de Policía Local de Vitacura, 11 de noviembre de 2009, rol No 114.876", en Revista de Derecho Privado, No 18, julio 2012, pp. $215-222$.

${ }^{3}$ Ekdahl, M. La doctrina de los actos propios: el deber jurídico de no contrariar conductas pasadas, Editorial Jurídica, Santiago, 1989, pp. 101-102.

${ }^{4}$ Salah, M. "Las doctrinas de los actos propios y de la protección a la apariencia: una mirada comparativa”, en Revista del Magíster y Doctorado en Derecho, Universidad de Chile, No 2, año 2008, p. 189.

${ }^{5}$ Padilla, R. "Por una correcta aplicación de la doctrina de los actos propios", en Revista Chilena de Derecho Privado, No 20, julio 2013, p. 140. 
consistente en una lesión injustificada del mismo, "la que proporciona una fuerte razón para poner de cargo del que se contradice el riesgo de su inconsistencia" 6 .

La sentencia que se comenta, constituye en uno de los casos en que la Corte encasilla la conducta del consumidor dentro de aquellas contrarias a la buena fe al establecer, en los considerandos $5^{\circ}$ y $6^{\circ}$, que su actuar atenta contra la doctrina de los actos propios. Sin embargo, no se trata de una aplicación de la teoría de los actos propios, en estricto sentido.

La Corte recurre a los presupuestos de la teoría como una forma de dar una especie de doble fundamento a su veredicto, cuestión que no es necesaria, bastando para dar sustento a su decisión, la argumentación que desarrolla en los demás considerandos.

En efecto, tal como lo señala Borda, la doctrina de los actos propios tiene carácter residual, esto quiere decir que no es aplicable cuando la ley ha contemplado otra solución de forma expresa ${ }^{7}$. Siguiendo el estudio de Padilla, se trataría de un caso que se acerca a aquellos en que el Tribunal incurre en un error de aplicación al omitir la residualidad o subsidiariedad $^{8}$. Digo que se acerca y no derechamente que incurre en dicho error, porque de la lectura de la sentencia no se desprende que se haya fallado exclusivamente en base a la teoría de los actos propios, sin hacerse cargo de la solución ya contemplada por la ley. Así las cosas, lo procedente es la argumentación en base a las reglas de responsabilidad civil, tal como se efectuó en los considerandos, $1^{\circ}$ al $4^{\circ}$ y se retomó en el considerando $7^{\circ}$, sin que haya sido menester recurrir a los presupuestos del venire contra factum propium.

No obstante lo anterior, lo rescatable es que la Corte ha tenido presente que si bien la LPDC se trata de un estatuto protector, a efectos del principio general de buena fe y sus manifestaciones, las partes se miran como iguales, es decir, a ambas les es exigible un comportamiento conforme a sus parámetros, sin importar que exista una asimetría que la ley intenta resolver, pues se trata de un principio general anterior a esa ratio legis.

${ }^{6}$ Corral, H. "La doctrina de los actos propios en el derecho de familia", en Cuadernos de extensión jurídica. Venire contra factum proprium. Escritos sobre fundamentación, alcance y límites de la doctrina de los actos propios. $\mathrm{N}^{\mathrm{o}}$ 18. Santiago: Universidad de los Andes. Facultad de Derecho [on line] http://corraltalciani.files. wordpress.com/2010/04/actospropios-familia.pdf [fecha de consulta: 29-3-14]

${ }^{7}$ Borda, A. La teoría de los actos propios. Buenos Aires, Abeledo-Perrot, 1993, p. 97.

${ }^{8}$ Padilla, R. "Por una correcta aplicación de la doctrina de los actos propios”, Op. cit., p. 176. 